\title{
OPEN Novel tonometer device distinguishes brain stiffness in epilepsy surgery
}

Aria Fallah ${ }^{1,2 \bowtie}$, Thirusivapragasam Subramaniam ${ }^{1}$, H. Westley Phillips ${ }^{1}$, Xavier Michalet ${ }^{3}$, Harry V. Vinters ${ }^{4}$, William H. Yong ${ }^{4}$, Joyce Y. Wu ${ }^{5}$, Noriko Salamon ${ }^{6}$, Benjamin M. Ellingson ${ }^{6}$, Anthony C. Wang ${ }^{1}$, Samuel D. Reyes ${ }^{1}$, George M. Ibrahim ${ }^{7}$, Alexander G. Weil ${ }^{8}$, Julia W. Chang ${ }^{1}$, Diana Babayan ${ }^{1}$, Jimmy C. Nguyen ${ }^{9}$, Eric Behnke ${ }^{1}$, Chi-Hong Tseng ${ }^{10}$ \& Gary W. Mathern ${ }^{1,11}$

Complete surgical resection of abnormal brain tissue is the most important predictor of seizure freedom following surgery for cortical dysplasia. While lesional tissue is often visually indiscernible from normal brain, anecdotally, it is subjectively stiffer. We report the first experience of the use of a digital tonometer to understand the biomechanical properties of epilepsy tissue and to guide the conduct of epilepsy surgery. Consecutive epilepsy surgery patients $(n=24)$ from UCLA Mattel Children's Hospital were recruited to undergo intraoperative brain tonometry at the time of open craniotomy for epilepsy surgery. Brain stiffness measurements were corrected with abnormalities on neuroimaging and histopathology using mixed-effects multivariable linear regression. We collected 249 measurements across 30 operations involving 24 patients through the pediatric epilepsy surgery program at UCLA Mattel Children's Hospital. On multivariable mixed-effects regression, brain stiffness was significantly associated with the presence of MRI lesion $(\beta=32.3,95 \% \mathrm{Cl} 16.3-48.2 ; p<0.001)$, severity of cortical disorganization $(\beta=19.8,95 \% \mathrm{Cl} 9.4-30.2 ; p=0.001)$, and recent subdural grid implantation ( $\beta=42.8,95 \% \mathrm{Cl} 11.8-73.8 ; p=0.009$ ). Brain tonometry offers the potential of real-time intraoperative feedback to identify abnormal brain tissue with millimeter spatial resolution. We present the first experience with this novel intraoperative tool for the conduct of epilepsy surgery. A carefully designed prospective study is required to elucidate whether the clinical application of brain tonometry during resective procedures could guide the area of resection and improve seizure outcomes.

The most common cause, and arguably the most challenging substrate of drug-resistant epilepsy in children, is cortical dysplasia $(C D)^{1-3}$. Surgical treatment depends on the ability of the preoperative investigations to determine a spatially well-defined focus for resection. It is particularly challenging to adequately identify and resect the full extent of $\mathrm{CD}$ for several reasons ${ }^{3}$ : First, magnetic resonance imaging (MRI) may not visualize the entirety of the lesion ("Tip of the iceberg phenomenon") or may be altogether "non-lesional"4-6. Second, electrocorticography $(\mathrm{ECoG})$ to determine the extent of $\mathrm{CD}$ is limited by issues related to spatial coverage, analysis protocols and biomarker selection ${ }^{7}$. Finally, $\mathrm{CD}$ appears identical to more normal brain during surgery, making intraoperative determination of the surgical borders difficult.

Despite the use of an intraoperative microscope, neurosurgeons cannot often visually differentiate normal tissue from CD, especially if the CD is subtle (i.e. Type I). However, some neurosurgeons palpate tissue stiffness

\footnotetext{
${ }^{1}$ Department of Neurosurgery, David Geffen School of Medicine at UCLA, 300 Stein Plaza, Suite 525, Los Angeles, CA 90095-6901, USA. '2Department of Pediatrics, David Geffen School of Medicine at UCLA, Los Angeles, USA. ${ }^{3}$ Department of Chemistry and Biochemistry, UCLA, Los Angeles, USA. ${ }^{4}$ Department of Pathology and Laboratory Medicine, David Geffen School of Medicine at UCLA, Los Angeles, USA. ${ }^{5}$ Division of Pediatric Neurology, David Geffen School of Medicine at UCLA, Los Angeles, USA. ${ }^{6}$ Department of Radiological Sciences, David Geffen School of Medicine at UCLA, Los Angeles, USA. ${ }^{7}$ Division of Neurosurgery, The Hospital for Sick Children, University of Toronto, Toronto, Canada. ${ }^{8}$ Division of Neurosurgery, Ste. Justine Hospital, University of Montreal, Montreal, Canada. ${ }^{9}$ Department of Clinical Neurophysiology, David Geffen School of Medicine at UCLA, Los Angeles, USA. ${ }^{10}$ Department of Medicine, David Geffen School of Medicine at UCLA, Los Angeles, USA. ${ }^{11}$ Department of Psychiatry and Biobehavioral Medicine, David Geffen School of Medicine at UCLA, Los Angeles, USA. ${ }^{\square}$ email: AFallah@mednet.ucla.edu
} 
to identify the boundaries of dysplastic tissue specially after the arachnoid is transgressed. Complete surgical resection of the structural lesion has been repeatedly shown to be the most important, and often the only, predictor of seizure freedom after epilepsy neurosurgery ${ }^{8-16}$. Complete resection is associated with $70-87 \%$ probability of seizure freedom while an incomplete resection is associated with 5-49\% probability of seizure freedom ${ }^{10}$. Surgical failures leading to seizure recurrences are costly, often require additional surgery, and are associated with continued elevated risks of seizure-related mortality and morbidity compared to those who achieve seizure remission ${ }^{17,18}$. Novel biomarkers to assist in the conduct of epilepsy surgery are welcome, yet very little innovation in surgical technique has been realized in the past 80 years.

Here, we investigate the utility of intraoperative real-time tonometry in identifying pathological tissue on the basis of brain stiffness. Disease-related changes in tissue stiffness are common in medicine ${ }^{19-21}$ including a variety of neurological disorders ${ }^{22,23}$. Epilepsy surgeons also qualitatively use tactile feedback to differentiate normal brain tissue from CD to guide the boundaries of surgical resection. Through this study, we investigate a novel application of a digital tonometer to in vivo human brain tissue and correlate the findings to imaging and histopathological abnormalities. The findings of this study should inform the conduct of a larger, prospective study to determine whether brain stiffness could be leveraged to improve outcomes for respective epilepsy surgery.

\section{Methods}

Consecutive patients identified for resective epilepsy surgery at UCLA Mattel Children's Hospital who met the eligibility criteria were invited to participate in this prospective observational study. All patients met ILAE definition of drug resistant epilepsy ${ }^{24}$. Two authors, A.F. and T.S., reviewed the relevant clinical history, results of non-invasive testing (including non-invasive video-EEG, 3-T MRI, Fludeoxyglucose (FDG)-Positron Emission Tomography (PET) and magnetoencephalography (MEG), when available) and pre-planned approximately 10 total points on the lateral surface of the brain that would be exposed during the surgery from both presumed more normal and more affected regions. The Institutional Review Board (IRB) at the University of California-Los Angeles (UCLA) approved all experimental protocols, the participation of human subjects (IRB\#17-001669) and all methods were carried out in accordance with these standard guidelines and regulations. Informed consent was obtained from all participants or their families including University of California HIPPA Research Authorization for Release of Personal Health Information for Research. We prepared a protocol a priori but did not register it.

Clinical data extraction. We recorded age at seizure onset, gender, race, number of anti-seizure drugs at time of surgery, age at surgery, presumed or histologically confirmed diagnosis, and the results of video EEG, MRI, FDG-PET, and MEG. We also recorded the severity of histological changes (dichotomized into mild cortical disorganization and Chaslin's gliosis vs. moderate or severe cortical dysplasia and other pathologies). To account for possible confounding variables, we also recorded side of surgery as well as physiological parameters including heart rate, systolic blood pressure, diastolic blood pressure, and arterial blood oxygenation at the time when brain stiffness was measured.

\section{Eligibility criteria. Inclusion Criteria}

- Participants eligible for surgery through the pediatric epilepsy program at UCLA Mattel Children's Hospital and/or operated on by the lead surgeon (AF).

- Undergoing resective epilepsy surgery for dysplastic (e.g., CD, TSC, Hemimegalencephaly, polymicrogyria) or non-dysplastic etiology (e.g., developmental tumors, gliosis, stroke, Rasmussen's encephalitis, Sturge-Weber Syndrome).

\section{Exclusion Criteria}

- Lesion of interest is in difficult-to-access regions such as paralimbic structures, insular, depth of sulcus, or interhemispheric locations.

Digital tonometer used to measure brain stiffness. The Diaton Tonometer probe is simple to use and reliable. It directly measures cortical stiffness without obscuring the surgical field. Its metal components are sterilizable via the autoclave. Only minimal contact is made with the gyrus of interest involving the tip and rod, minimizing contamination risk while providing high-precision (millimeter) spatial resolution (Fig. 1). This degree of precision allows accurate comparisons to be made with histopathologic analysis. The measured pressure $(\mathrm{P})$ is not the same as Young's modulus $(\mathrm{E})$, and therefore cannot be compared directly to the literature values for Young's modulus of brain tissues. It is true that $\mathrm{E}$ is related to $\mathrm{P}$ in a non-linear fashion and that higher P means greater stiffness, but the exact relationship between these two variables is yet to be investigated.

Our technique to obtain brain tonometry readings. Following the craniotomy, the dura is reflected facilitating a wide exposure to the lateral surface of the neocortex. Prior to ECoG, we perform brain tonometry on the crown of the gyri using the digital tonometer, which is approved by the U.S. Food and Drug Administration to measure intraocular pressure. The digital tonometer probe's body is disinfected and inserted in a sterile plastic bag. The sterilized metal components are then attached to the probe through a small slit in the plastic drape. The device provides a digital readout of "pressure" and has a guaranteed maximum measurement error of $2 \mathrm{~mm} \mathrm{Hg}$ in the range 5-20 $\mathrm{mm} \mathrm{Hg}$ and of $10 \%$ in the range $20-60 \mathrm{~mm} \mathrm{Hg}$. The device's principle consists in measuring the maximum deformation $d$ of the tissue impacted by a small free-falling metal rod of mass $m$. Given 

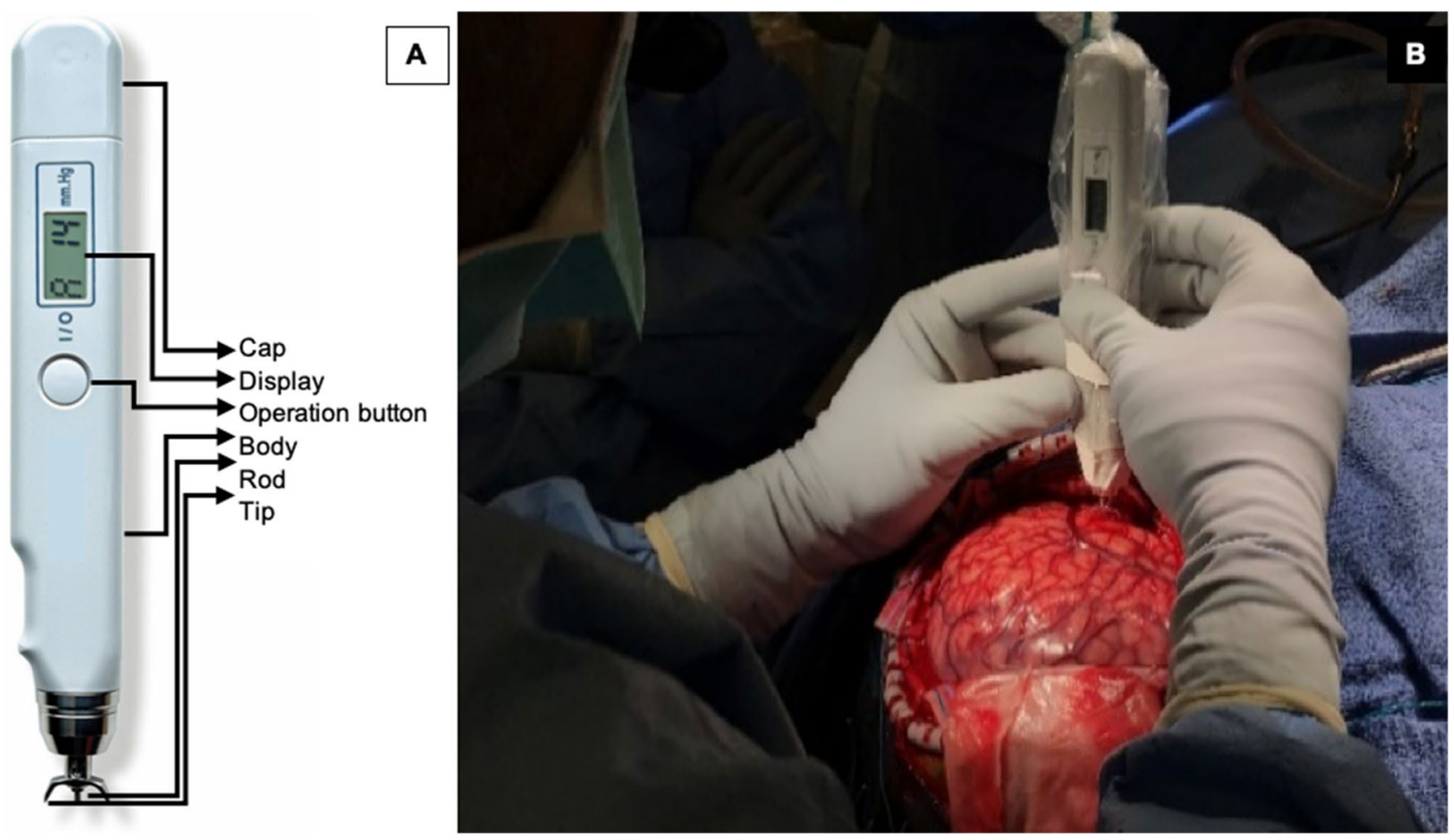

Figure 1. (A) The components of the digital tonometer (only the center rod and crescent-shaped tip make contact with the brain); and (B) intraoperative photograph demonstrating its use.

the known surface area $S$ of the contact zone, the reported pressure $P$ is given by $P=m \times g / S$, where $g$ is the acceleration of the rod due to gravity and $S$ is related to the deformation $d$. The reported pressure can then in principle be related to Young's modulus $E$ of the tissue (assumed to be isotropic), a direct measurement of its stiffness.

Selecting regions for brain tonometry. We obtained stiffness measurements in pre-planned presumed more affected and less affected areas of the brain based on criteria stated previously ${ }^{25}$. We also obtained measurements from distant brain locations including recordings from each exposed lobe (Fig. 1). For each reading, we saved the stereotactic point onto our frameless neuronavigation software to facilitate its correlation to MRI and FDG-PET abnormalities. On average, we obtained 8 to 10 points per surgery. Each digital readout on the tonometer is an average of 4 to 6 individual pressure readings in millimeters of mercury $(\mathrm{mm} \mathrm{Hg})$. The device audibly alerts the operator when each measurement is consistent with the previous, therefore signifying high reproducibility of the readings. If the planned resection involved regions were brain stiffness was measured, we sent separate biopsies of these regions for histological analysis. We anonymously labeled these brain regions (such as brain region 1) to avoid inadvertently influencing the diagnosis. Brain stiffness measurements were all performed by the operating surgeon, (A.F.) and transcribed during surgery by the research fellow, T.S.

Design considerations and statistical methods. It is important to note that there are no normal controls for this type of research. Post-mortem brain tissue undergoes irreversible biomechanical tissue changes, and there are no normal patients that undergo neurosurgical operations that might provide a good comparison. To address this issue, we use an experimental design that involves both within-participant, and between-participant comparisons. For continuous data, we report means and standard deviations. For dichotomous outcomes, we report frequencies and percentages. Means and standard deviations (SD) for brain stiffness measures are compared for each categorical covariate by a T-test or ANOVA (when there were more than 2 categories). We reported our findings using a coefficient $(\beta), 95 \%$ Confidence Intervals $(C I)$ and $p$ values. To better account for the clusters of related data from each participant, we performed a linear mixed effects model with stepwise forward variable selection to identify covariates that independently predict brain stiffness. We created boxplots to compare the stiffness distribution by pathology and severity of histopathological abnormality. Receiver operating characteristic (ROC) analysis was performed to evaluate brain stiffness as a biomarker for underlying MRI abnormality, FDG-PET hypometabolism, and severity of histopathological abnormality, respectively. By conventional criteria, we considered results statistically significant if two-sided p values were less than 0.05 . All statistical analyses were performed using IBM SPSS Version 25; IBM Corp. 


\begin{tabular}{|c|c|c|c|c|c|c|c|c|}
\hline Pt. no. & $\begin{array}{l}\text { Age at surgery / } \\
\text { gender }\end{array}$ & Race & Age of seizure onset & \# of AEDs & $\begin{array}{l}\text { Histopathological } \\
\text { diagnosis }\end{array}$ & $\begin{array}{l}\text { EEG localization / } \\
\text { lateralization }\end{array}$ & MRI abnormality & $\begin{array}{l}\text { FDG-PET } \\
\text { (hypometabolism) }\end{array}$ \\
\hline 1 & $3 \mathrm{y} \mathrm{M}^{*}$ & Caucasian & $8 \mathrm{~m}$ & 1 & CD Ic & Right T & Polymicrogyria & R hemispheric \\
\hline 2 & $4 y M^{*}$ & Hispanic & $6 w$ & 2 & Tuber & Right F,T,C & $\begin{array}{l}\text { Multiple cortical and } \\
\text { subcortical tubers }\end{array}$ & $\begin{array}{l}\text { Multiple bilateral } \\
\text { foci }\end{array}$ \\
\hline 3 & $15 y$ F & Middle Eastern & $40 \mathrm{~d}$ & 2 & CD II & Left C,T,F & $\begin{array}{l}\text { T2/FLAIR hyper- } \\
\text { intensity in left } \\
\text { mesial and anterior } \\
\text { temporal lobe }\end{array}$ & L Temporal lobe \\
\hline 4 & 3y F & Caucasian & $9 \mathrm{~m}$ & 2 & $\begin{array}{l}\text { Remote infarction } \\
\text { and gliosis }\end{array}$ & Left $\mathrm{H}$ & $\begin{array}{l}\text { Chronic infarction in } \\
\text { L MCA territory }\end{array}$ & L MCA territory \\
\hline 5 & $2 y F$ & Caucasian & $16 \mathrm{~m}$ & 1 & $\begin{array}{l}\text { Ganglioglioma } \\
\text { WHO Grade I, CD } \\
\text { IIIb }\end{array}$ & Left C & $\begin{array}{l}\text { T2 hyperintensity } \\
\text { in L amygdala and } \\
\text { mesial temporal lobe }\end{array}$ & $\begin{array}{l}\text { Left anteromedial } \\
\text { Temporal Lobe }\end{array}$ \\
\hline 6 & $5 y F$ & Hispanic & $2 y$ & 4 & CD IIa & Bifrontal & $\begin{array}{l}\text { FLAIR hyperinten- } \\
\text { sity in R orbitofrontal } \\
\text { region }\end{array}$ & Symmetric cerebellar \\
\hline 7 & $6 y \mathrm{M}$ & Mixed & $4 \mathrm{~m}$ & 2 & Ulegyria and CD IIId & Left P & \begin{tabular}{|l|} 
Restricted diffusion \\
within cortex of L \\
Parietal and Occipital \\
Lobe
\end{tabular} & $\begin{array}{l}\text { L Temporal, Parietal, } \\
\text { and Occipital Lobes }\end{array}$ \\
\hline 8 & $20 \mathrm{y} \mathrm{M}$ & Caucasian & $5 y$ & 4 & Gliosis & Bilateral F,T & $\begin{array}{l}\text { Subtle GW differen- } \\
\text { tiation in L Temporal } \\
\text { pole }\end{array}$ & L Temporal Lobe \\
\hline 9 & $22 y \mathrm{~F}$ & Caucasian & $11 \mathrm{y}$ & 3 & $\mathrm{CD}^{* *}$ & Right C,T,P & $\begin{array}{l}\text { Tiny foci of T2/ } \\
\text { FLAIR L periven- } \\
\text { tricular hyperin- } \\
\text { tensity }\end{array}$ & None \\
\hline 10 & $4 y \mathrm{~F}$ & Black & $4 y$ & 1 & $\begin{array}{l}\text { Angiocentric Glioma } \\
\text { WHO Grade I }\end{array}$ & Left F,T,C & $\begin{array}{l}\text { Cortically based } \\
\text { mass in L frontal } \\
\text { operculum }\end{array}$ & L Temporal Lobe \\
\hline 11 & $12 \mathrm{y} \mathrm{M}$ & Caucasian & $2 y$ & 3 & $\mathrm{CD}^{* *}$ & Left C & None & None \\
\hline 12 & $14 \mathrm{y} \mathrm{M}$ & Caucasian & $7 y$ & 2 & $\mathrm{CD}^{* *}$ & Left $\mathrm{T}$ & $\begin{array}{l}\text { T2/FLAIR hyperin- } \\
\text { tensity in L Temporal } \\
\text { Lobe }\end{array}$ & $\begin{array}{l}\text { R greater than L } \\
\text { Temporal Lobe }\end{array}$ \\
\hline 13 & $11 \mathrm{y} \mathrm{F}$ & Hispanic & $3 \mathrm{~m}$ & 3 & CD IIa & Left F & $\begin{array}{l}\text { Residual FCD L } \\
\text { anterior insula }\end{array}$ & None \\
\hline 14 & $64 y \mathrm{~F}$ & Asian & $1 \mathrm{~m}$ & 3 & Acute Infarction** & Diffuse & R Frontal Infarction & R Frontal Lobe \\
\hline 15 & $4 y \mathrm{M}$ & Caucasian & $4 \mathrm{~d}$ & 3 & Remote Infarction & Right $\mathrm{H}$ & $\begin{array}{l}\text { R hemispheric } \\
\text { encephalomalacia }\end{array}$ & $\begin{array}{l}\text { R Frontal and Tem- } \\
\text { poral Lobe }\end{array}$ \\
\hline 16 & $13 y \mathrm{y}$ & Hispanic & $1 \mathrm{~m}$ & 3 & CD IIa & Right $\mathrm{H}$ & $\begin{array}{l}\text { Cortical thickening } \\
\text { of R Frontal Lobe }\end{array}$ & $\begin{array}{l}\text { R Posterior Tem- } \\
\text { poral and Inferior } \\
\text { Parietal }\end{array}$ \\
\hline 17 & $10 \mathrm{~m} \mathrm{M}$ & Middle Eastern & $6 \mathrm{~m}$ & 3 & CD IIa & Non-lateralizing & Normal & R Occipital Lobe \\
\hline 18 & $11 \mathrm{y} \mathrm{M}$ & Hispanic & $10 y$ & 2 & CD IIb & Right F,T,P & $\begin{array}{l}\text { R Temporal Lobe } \\
\text { Lesion }\end{array}$ & R Temporal Lobe \\
\hline 19 & $15 y \mathrm{~F}$ & Caucasian & $3 \mathrm{~m}$ & 1 & $\begin{array}{l}\text { Ganglioglioma and } \\
\text { CD IIIb }\end{array}$ & Right $\mathrm{T}$ & $\begin{array}{l}\text { L Temporal lobe } \\
\text { mass }\end{array}$ & L Temporal Lobe \\
\hline 20 & $15 \mathrm{~m} \mathrm{~F}$ & Hispanic & $1 \mathrm{~m}$ & 4 & CD IIa & Right $\mathrm{T}$ & $\begin{array}{l}\text { R temporo-parietal } \\
\text { dysplasia }\end{array}$ & $\begin{array}{l}\text { R Temporal and } \\
\text { Occipital Lobes }\end{array}$ \\
\hline 21 & $8 y$ F & Caucasian & $3 \mathrm{~m}$ & 5 & CD Ic & Left $\mathrm{H}$ & $\begin{array}{l}\text { Remote L functional } \\
\text { hemispherectomy }\end{array}$ & $\begin{array}{l}\text { R hemisphere, } \mathrm{L} \\
\text { Temporal and Pari- } \\
\text { etal Lobes }\end{array}$ \\
\hline 22 & $15 \mathrm{~m} \mathrm{~F}$ & Asian & $3 \mathrm{~m}$ & 2 & Tuber & Right F,C & $\begin{array}{l}\text { Multiple cortical and } \\
\text { subcortical tubers }\end{array}$ & $\begin{array}{l}\text { Multiple bilateral } \\
\text { foci }\end{array}$ \\
\hline 23 & $2 \mathrm{yM}$ & Hispanic & $2 \mathrm{~m}$ & 3 & CD IIb & Right T,P,O & $\begin{array}{l}\text { Right parieto-occipi- } \\
\text { tal dysplasia }\end{array}$ & $\begin{array}{l}\text { R Parietal and } \\
\text { Occipital Lobes }\end{array}$ \\
\hline 24 & $15 \mathrm{~m} \mathrm{M}$ & Hispanic & $3 \mathrm{~m}$ & 4 & Tuber & Right F & $\begin{array}{l}\text { Multiple cortical and } \\
\text { subcortical tubers }\end{array}$ & R Frontal Lobe \\
\hline 25 & $3 y F$ & Hispanic & $36 \mathrm{~m}$ & 4 & $\begin{array}{l}\text { Rasmussen's } \\
\text { Encephalitis }\end{array}$ & Right F,C & $\begin{array}{l}\text { R peri-sylvian and } \\
\text { frontal lobe atrophy }\end{array}$ & R hemisphere \\
\hline
\end{tabular}

Table 1. Characteristics of participants included in the study. F Frontal, $C$ Central, $H$ Hemisphere, $T$ Temporal, $P$ Parietal. ${ }^{\star}$ Participant had a prior craniotomy. ${ }^{\star *}$ Presumed diagnosis (No pathological specimen).

\section{Results}

We attempted brain stiffness recordings 31 times across 25 consecutive participants (Median age at surgery was 12 years; Range was 1-64 years) and obtained 249 data points (Table 1). The device malfunctioned due to blood contamination of the rod preventing measurements for participant \#5 leaving 24 participants that contributed data to this study. The median age of seizure onset was 2 years (Range $0.11-64$ years). Forty-five percent $(n=11)$ of the participants were female. The median duration of seizures was 4 years (Range 4 days to 15 years). From 30 


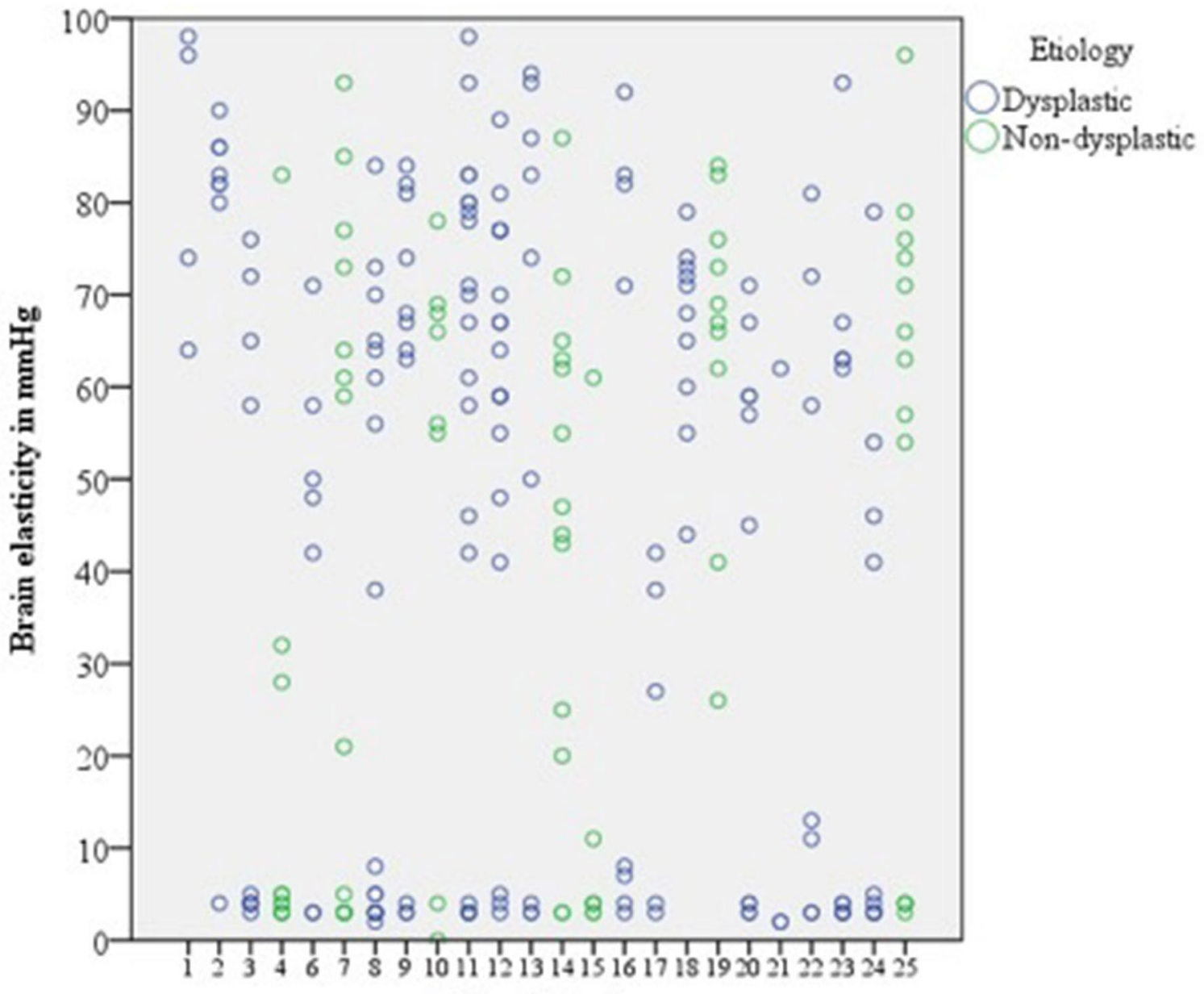

\section{Patient Number}

Figure 2. Scatter plot of raw data across 24 patients demonstrating a wide variability in brain stiffness measurements within participants.

total operations, 1 was for an anatomic hemispherectomy, 4 were for a functional hemispherectomy, 15 were for a cortical resection, 1 was for a cortical resection plus insertion of a Responsive Neurostimulation (RNS) device, 3 were for implantation of an RNS device only, and 6 were for invasive-electroencephalography (subdural grid strip and depth electrodes) alone. Three patients (13\%) have had previous craniotomies. The underlying epileptogenic substrate was CD for 14 patients (58\%), tumors for 3 patients (13\%), infarction for 3 patients (13\%), TSC for 3 patients (13\%) and Rasmussen's Encephalitis for 1 patient (4\%). For 3 cases, we presumed a diagnosis of $\mathrm{CD}$ although no pathological specimen was available for confirmation; these patients underwent an RNS device implantation only. No infection or side effect was recorded in any patient due to brain tonometry. We estimate that our study protocol added $30 \mathrm{~min}$ to the surgical time although this was not prospectively recorded.

Wide variability in effective brain stiffness was observed within individual participants (Fig. 2). In this cohort, the median brain elasticity was $55.0 \mathrm{~mm} \mathrm{Hg}$ while the standard deviation was $33.2 \mathrm{~mm} \mathrm{Hg}$. In all patients, except 1,18 and 19, we consistently found a tight cluster of measurements with low stiffness (Mode: 3 mm Hg; Mean $(\mathrm{SD})=3.6(1.0) \mathrm{mm} \mathrm{Hg}$ ). We presume this to correspond to more normal areas of the brain. In instances where this region was biopsied, this corresponded to mild cortical disorganization or Chaslin's gliosis (Fig. 3).

Through univariable analysis, we found several covariates associated with higher brain stiffness including age of seizure onset (greater than 2 years), duration of seizures (greater than 7 years, prior craniotomy, recent subdural grid implantation, lesional MRI, and severity of cortical disorganization (Table 2). These covariates, all with $\mathrm{p}$ values of less than 0.20 , were selected for multivariable hierarchical forward stepwise regression. A significant regression equation was found $(\mathrm{F}(4,32)=18.268 ; p<0.001)$, with an adjusted $R^{2}$ of 0.683 (Standard Error (SE) 18.961). Presence of MRI lesion ( $\beta=32.3$, 95\%CI 16.3-48.2; $p<0.001)$, severity of cortical disorganization $(\beta=19.8,95 \%$ CI 9.4-30.2; $p=0.001)$, and recent subdural grid $(\beta=42.8,95 \%$ CI 11.8-73.8; $p=0.009)$ were all independent predictors of brain stiffness. The high adjusted regression model fit $R^{2}$ value suggests a high predictive ability of brain stiffness using the above variables. Of note, the presence of MRI lesion and severity of cortical disorganization together explained greater than half the variance of brain stiffness (adjusted $R^{2}$ of 0.607 (SE 21.124)).

For determining the utility of brain stiffness identifying underlying MRI lesion, FDG-PET hypometabolism and severity of histopathological changes (dichotomized to mild vs. moderate/severe cortical disorganization), 


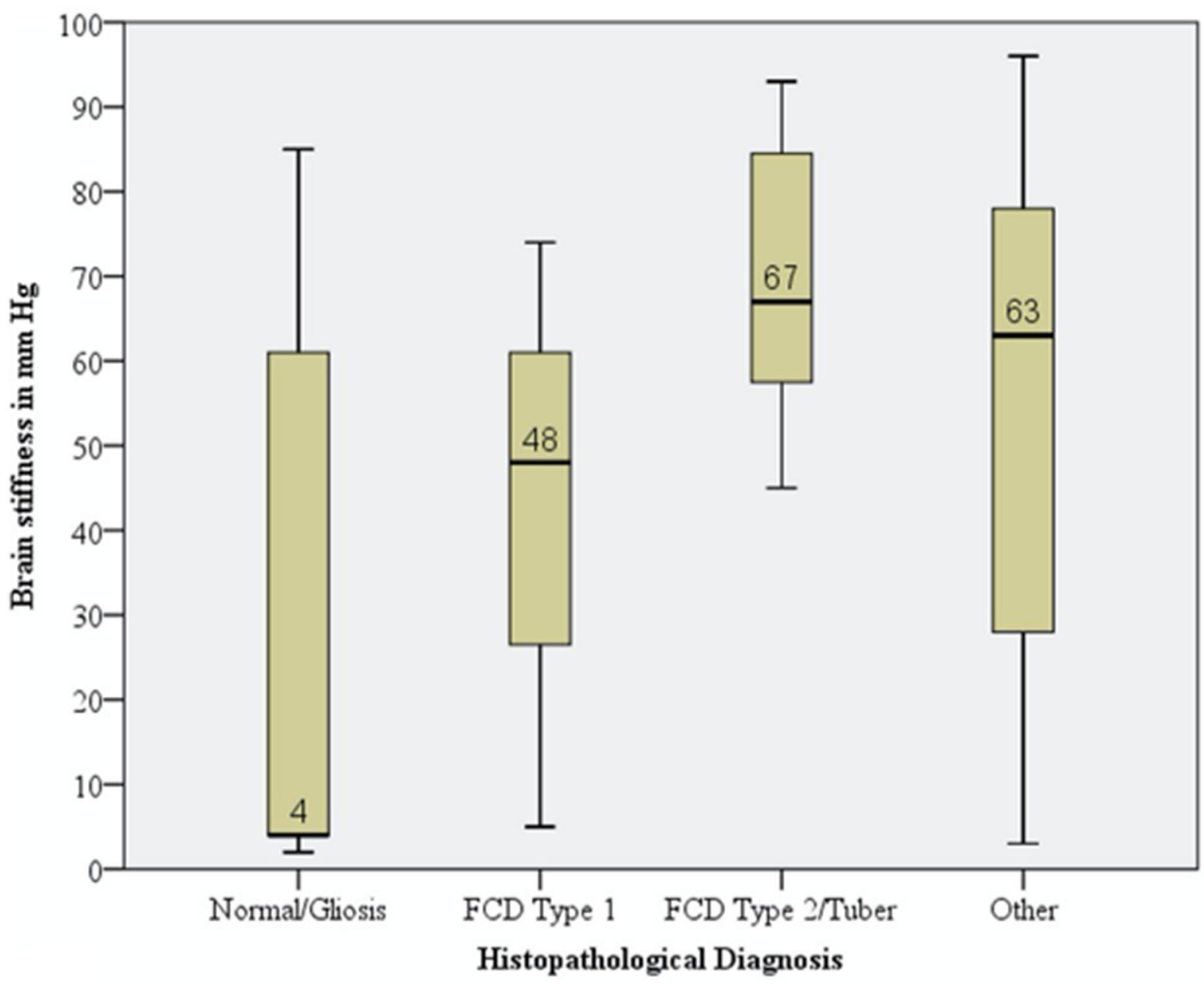

Figure 3. Boxplot of brain stiffness demonstrating mean, standards deviation and range in $\mathrm{mm} \mathrm{Hg}$ by histopathological diagnosis.

we created a ROC plot for each imaging modality and obtained an area under the curve (AUC) of 0.63 (95\% CI $0.54-0.71 ; p=0.007), 0.57$ (95\% CI $0.48-0.65 ; p=0.126)$ and 0.85 (95\% CI $0.72-0.98 ; p<0.001)$, respectively (Fig. 4). This analysis suggests that brain stiffness is a better biomarker for structural brain abnormalities than functional brain abnormalities based on traditional neuroimaging modalities. With a cutoff value of $60.5 \mathrm{~mm}$ $\mathrm{Hg}$, there is $60 \%$ sensitivity and $60 \%$ specificity in detecting the presence of an underlying MRI lesion. Brain stiffness values have the greatest utility to serve as a biomarker for determining the severity of histopathological abnormality of the underlying neocortex. With a cutoff value of $16.5 \mathrm{~mm} \mathrm{Hg}$, there is $100 \%$ sensitivity and $71 \%$ specificity in detecting moderate/severe cortical disorganization from mild cortical disorganization.

\section{Discussion}

To our knowledge this is the first study to measure in vivo brain stiffness in epilepsy surgery patients. We report several novel findings. First, there is a large degree of variability in regional brain stiffness within participants. In participant 3 for example, this variability was demonstrated as adjacent gyri can have striking differences in stiffness (e.g., see point 7 and 12) (Fig. 5). Our data suggest that more than half of this variance is explained by histopathological severity and presence of MRI lesion alone. Dysplastic lesions induce changes in gene expression that alter molecular and cellular constituents in structurally normal brain regions ${ }^{26}$, perhaps secondarily affecting brain stiffness.

Second, regardless of the participant's age at surgery, race, gender, epilepsy substrate, and lobe, there is a very tight range of normal brain stiffness corresponding to about $3 \mathrm{~mm} \mathrm{Hg}$ on this device. Given its consistency, we believe that this likely reflects the stiffness of normal brain. Our study is similar to the findings reported by Chauvet et al. who found lesional tissue to have higher stiffness compares to more normal brain ${ }^{27}$. A direct comparison of the values is not possible at this stage as the two methods do not measure the same variable.

Third, we observed that for participants with CDs, and especially for Type I, they commonly had widespread abnormalities in brain stiffness even at distant sites (with no MRI or FDG-PET abnormality) from the resected seizure-onset zone. Taylor et al. suggested that epileptogenic CD is often distributed and may be not-contiguous ${ }^{28}$. Even within the confines of a single resected lobe, the abnormality is sometimes disseminated rather than 


\begin{tabular}{|c|c|c|c|c|c|}
\hline $\begin{array}{l}\text { Independent } \\
\text { variable }\end{array}$ & \multicolumn{2}{|l|}{ Mean (SD) mm Hg } & \multicolumn{2}{|l|}{ Mean (SD) mm Hg } & $p$ value \\
\hline $\begin{array}{l}\text { Age of seizure onset } \\
\text { (dichotomized) }\end{array}$ & \multicolumn{2}{|l|}{$<2 y 36.0(35.0)$} & \multicolumn{2}{|l|}{$\geq 2 y 49.8(30.0)$} & $<0.001^{* *}$ \\
\hline $\begin{array}{l}\text { Duration of seizures } \\
\text { (dichotomized) }\end{array}$ & \multicolumn{2}{|l|}{$<7 y 42.3(32.3)$} & \multicolumn{2}{|l|}{ z7y $44.6(34.5)$} & $0.110^{\star *}$ \\
\hline $\begin{array}{l}\text { No. of AEDs } \\
\text { (dichotomized) }\end{array}$ & \multicolumn{2}{|l|}{$<250.0(31.9)$} & \multicolumn{2}{|l|}{$\geq 242.3(33.3)$} & 0.230 \\
\hline $\begin{array}{l}\text { Age at surgery } \\
\text { (dichotomized) }\end{array}$ & \multicolumn{2}{|l|}{$<12 y 40.7$ ( 33.7$)$} & \multicolumn{2}{|l|}{$\geq 12 y 46.3(32.3)$} & 0.211 \\
\hline Gender & \multicolumn{2}{|l|}{ Female 41.8 (32.2) } & \multicolumn{2}{|l|}{ Male $44.5(34.0)$} & 0.517 \\
\hline Prior Craniotomy & \multicolumn{2}{|l|}{ No $41.0(32.6)$} & \multicolumn{2}{|l|}{ Yes $56.0(33.7)$} & $0.011^{* *}$ \\
\hline Side of Brain & \multicolumn{2}{|l|}{ Left $43.2(33.7)$} & \multicolumn{2}{|l|}{ Right 43.3 (32.8) } & 0.976 \\
\hline Lobe & Frontal $47.6(35.1)$ & Temporal 39.7 (30.6) & Parietal $40.6(31.4)$ & Occipital 25.3 (40.6) & 0.238 \\
\hline $\begin{array}{l}\text { Post invasive EEG } \\
\text { implant (grid, strip } \\
\text { or depth) }\end{array}$ & \multicolumn{2}{|l|}{ No 40.7 (33.1) } & \multicolumn{2}{|l|}{ Yes $56.0(30.5)$} & $0.007^{* *}$ \\
\hline MRI & \multicolumn{2}{|l|}{ No Lesion 30.6 (33.0) } & \multicolumn{2}{|l|}{ Lesion 54.5 (31.9) } & $0.058^{\star *}$ \\
\hline FDG-PET & \multicolumn{2}{|l|}{ Isometabolic 41.8 (33.2) } & \multicolumn{2}{|l|}{ Hypometabolic 48.1 (32.9) } & 0.615 \\
\hline Diagnosis & \multicolumn{2}{|l|}{ Non-dysplastic 40.3 (32.2) } & \multicolumn{2}{|l|}{ Dysplastic $44.5(33.6)$} & 0.610 \\
\hline Pathology & Normal/Gliosis 26.4 (32.4) & CD I $42.3(34.8)$ & CD II/Tuber 69.7 (16.0) & Other $50.6(34.9)$ & $0.009^{* *}$ \\
\hline $\begin{array}{l}\text { Pathology (dichoto- } \\
\text { mized) }\end{array}$ & \multicolumn{2}{|l|}{ Less affected 23.6 (31.4) } & \multicolumn{2}{|l|}{ More affected 63.9 (23.1) } & $0.034^{\star *}$ \\
\hline $\begin{array}{l}\text { Histopathological } \\
\text { Severity }\end{array}$ & Mild 23.8 (31.3) & Moderate $67.7(17.5)$ & \multicolumn{2}{|l|}{ Severe $73.0(13.8)$} & $<0.001^{* *}$ \\
\hline
\end{tabular}

Table 2. Brain elasticity measures by covariates. T-test performed for dichotomized variables. ANOVA test performed when variables had more than 2 categories. ${ }^{*}$ For continuous variables, the cut-point was set at the median value. ${ }^{* \star}$ Statistically significant association with brain elasticity on univariate analysis. These variables were used for the multi-variate analysis.
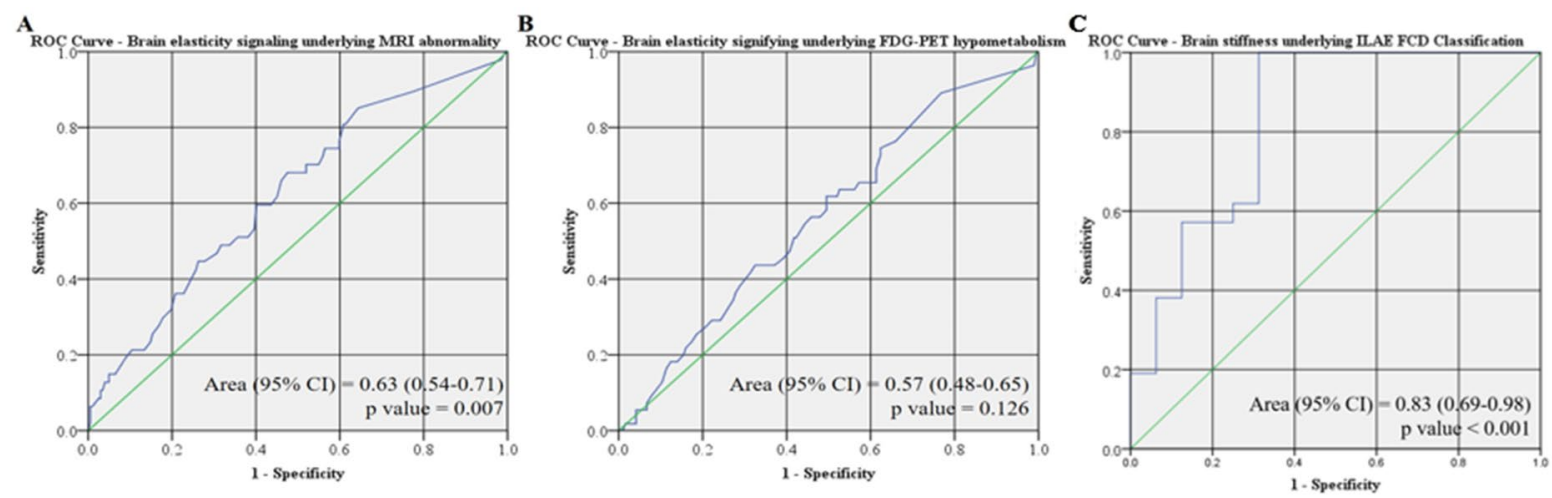

Figure 4. Receiver operator curve for brain tonometry as a diagnostic tool for detection of underlying (A) MRI abnormality, (B) FDG-PET hypometabolism; and (C) ILAE FCD Classification (normal/gliosis vs. Type 1/Taype 2 FCD).

confined to a single region. The findings of our study support this notion, which can be further tested through a biopsy of these regions in future studies.

Prior studies on human brain stiffness. There are a number of in vivo and ex vivo studies on brain stiffness in animals ${ }^{29}$ and of ex vivo studies in humans, but we are aware of only two research teams that have performed in vivo direct measurements of human brain stiffness ${ }^{30,31}$. The first group applied a light aspiration device to the surface of an adult patient's brain with a brain tumor and used an adjacent mirror that reflected the image to an external camera to measure the deformation of this tissue ${ }^{32}$. Although the primary aim was to assess applied pressure by synchronizing the video and pressure recording, the authors reported that this was a difficult experiment to perform with concerns regarding measurement reproducibility and challenges with sterilization. Another group published on the utilization of an ultrafast ultrasonic device to measure shear wave electrography as a means to characterize brain tumor subtypes and differentiate this from the surrounding normal brain ${ }^{38}$. This device obscures the surgical field, has a limited field of view and provides low-spatial resolution. Further, it does not provide immediate quantitative feedback to the surgeon. Other studies of brain stiffness are 


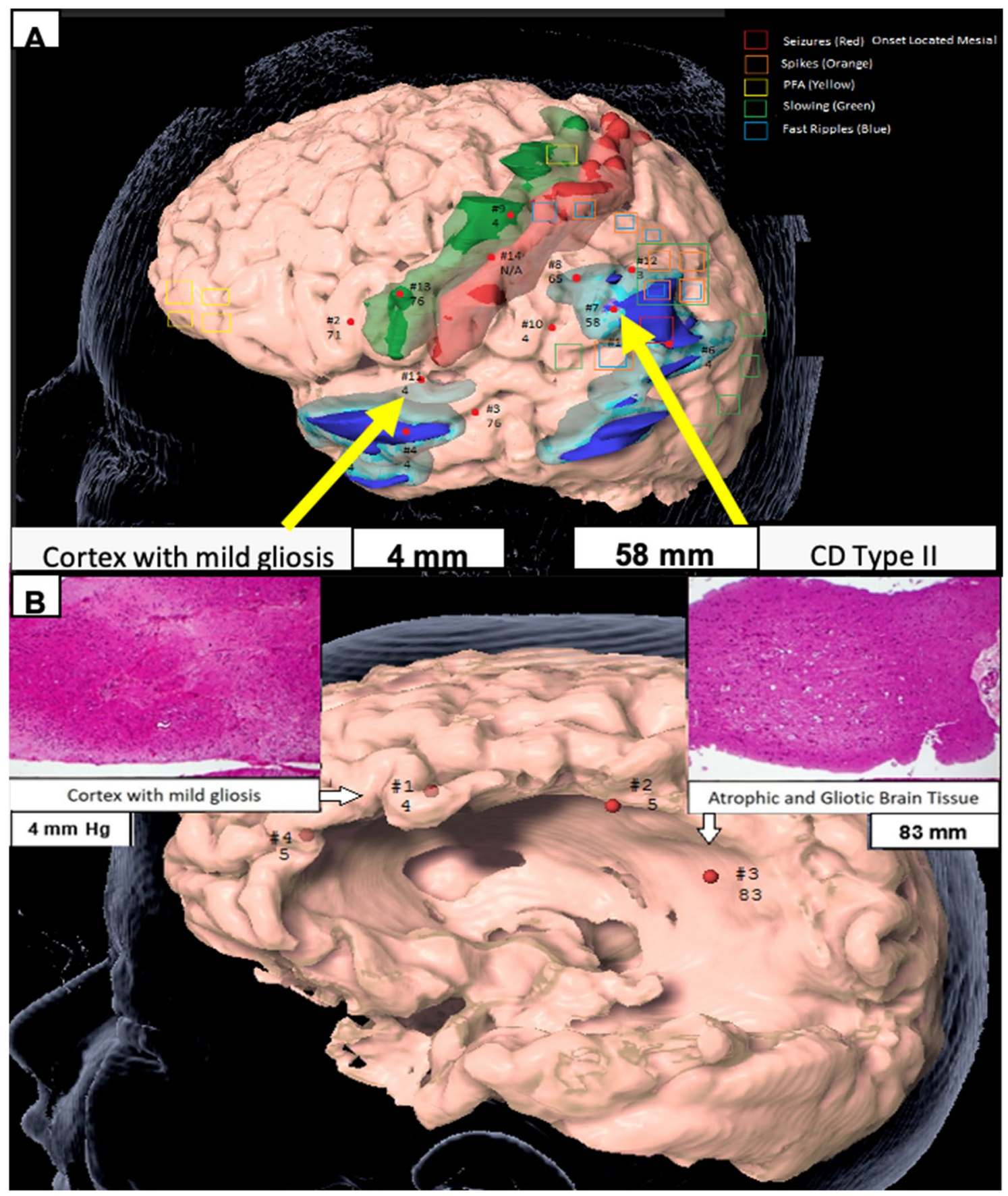

Figure 5. (A) Participant \#3. Region of high stiffness corresponded to CD Type II while region of low stiffness corresponded to cortex with mild gliosis. Green is primary motor cortex. Red is primary sensory cortex. Light and dark blue are regions of PET hypometabolism and different thresholds. Legend describes the EEG data from the subdural grid and strip electrodes, and (B) participant \#4. MRI biopsy location from a region of low stiffness (left) compared to an area of high stiffness (right) as measured using digital tonometry, and corresponding histopathology (H\&E, magnification × 10). Figure designed using BrainLab iPlan Net 3.6.0 https://www.brainlab. com/radiosurgery-products/iplan-rt-treatment-planning-software/.

reported using non-invasive MR-based techniques such as MR Elastography (MRE) with no objective intraoperative verification ${ }^{21,23,32}$. Post-mortem and animal studies ${ }^{33,34}$ are not necessarily comparable to in-vivo studies in the human pediatric brain.

Mechanism of variation in human brain stiffness. We postulate that the mechanistic origin of variations in stiffness correlates to underlying tissue microstructure and is altered by the following: (1) Individual neurons: Increased neuronal density is associated with increased tissue stiffness ${ }^{35,36}$; (2) The Extracel- 
lular Matrix: Increased tissue acidity, as a result of increased $\mathrm{CO}_{2}$ concentrations, is associated with increased stiffness ${ }^{37}$; and (3) The cellular cytoskeleton and other structure forming proteins: The human brain undergoes significant alterations especially over the first 4 years of life in which neurons exhibit more extensive dendritic and axonal branching and synapse formation accompanied by a rise in the lipid content as axonal segments are myelinated ${ }^{38}$. Increased myelin content increases stiffness, perhaps due to its high lipid content, leaving less space for the polymeric/structure-forming material such as collagen, actin, and tubulin ${ }^{37}$.

Potential clinical implications. In less-well localized epilepsy, certain pediatric epilepsy groups, including ours, frequently determine surgical resection boundaries by avoiding eloquent brain regions. The argument is that larger resections may be associated with a higher likelihood of achieving seizure freedom, provided the risks of resecting this tissue is acceptably low ${ }^{39}$. However, this approach may lead to larger-than-necessary resections of more normal cortex or lead to a lower probability of seizure freedom when CD involving eloquent cortex is intentionally preserved ${ }^{36}$. Through a more tailored surgical approach utilizing measures of brain stiffness, we suspect that improved likelihood of seizure freedom can be achieved through more complete resections of $\mathrm{CD}$ and, alternatively, the same likelihood of seizure freedom can be obtained in children undergoing smaller cortical resections. Lastly, a novel approach utilizing MRE and brain tonometry to identify areas increased brain stiffness could prevent the need for invasive monitoring with grids, strip and depth electrodes in select cases.

Strengths and limitations of the digital tonometer. Current technical shortcomings of this device include its limited ability to be used on exposed lateral brain surface and, thus far, not being able to sample the difficult-to-access regions of the brain such as the insular or interhemispheric regions as well as subcortical structures. We are also limited to recording in regions in which the device can be held exactly vertical, a constraint imposed by the requirement that the tonometer's rod needs to undergo free fall without friction against the walls of the device. Anatomical structures such as the sulci and blood vessels preclude recording from all exposed brain surfaces. Further, the depth of cortex from which the tonometer probe measures stiffness is unknown but most likely limited to a few millimeters. The range of stiffness that is suitable at measuring reliably might be too limited to cover the complete range of brain tissue stiffness that might be encountered. In its current form, the device is cumbersome only yielding point readings. Furthermore, our study is limited by our low patient number and inability to directly correlate our findings with emerging MRE tools. There are also many strengths to using the digital tonometer. Recordings are in real-time, have high spatial resolution and reproducibility. Compared to other intraoperative image-guided neuronavigation methods, this tool is not impacted by brain-shift. Lastly, the components that touch the cortical surface can be sterilized.

\section{Conclusion}

Through this preliminary study, we have demonstrated feasibility of an easy-to-use handheld tool to obtain real-time in vivo measurements of human brain stiffness during open craniotomy. We have identified highly consistent normal values of human brain stiffness across age, gender, ethnicity, and epilepsy substrate within the confines of our patient population. Our early experience demonstrates that underlying MRI lesion, severity of cortical disorganization and recent subdural grid implantation are highly associated with regions of increased brain stiffness. Future multicenter studies are required to determine whether the identification and resection of abnormally stiff areas may result in greater success of epilepsy surgery in patients with CD.

Received: 21 February 2020; Accepted: 12 November 2020

Published online: 01 December 2020

\section{References}

1. Gaitanis, J. N. \& Donahue, J. Focal cortical dysplasia. Pediatr. Neurol. 49, 79-87 (2013).

2. Moosa, A. N. V. \& Gupta, A. Outcome after epilepsy surgery for cortical dysplasia in children. Child's Nerv. Syst. 30, 1905-1911 (2014).

3. Palmini, A. \& Holthausen, H. Focal malformations of cortical development. In Handbook of Clinical Neurology 549-565 (2013). https://doi.org/10.1016/B978-0-444-52891-9.00058-0.

4. Kim, Y. H. et al. Neuroimaging in identifying focal cortical dysplasia and prognostic factors in pediatric and adolescent epilepsy surgery. Epilepsia 52, 722-727 (2011).

5. Wang, Z. I. et al. The pathology of magnetic-resonance-imaging-negative epilepsy. Mod. Pathol. 26, 1051-1058 (2013).

6. Lerner, J. T. et al. Assessment and surgical outcomes for mild type I and severe type II cortical dysplasia: a critical review and the UCLA experience. Epilepsia 50, 1310-1335 (2009).

7. Raymond, A. A. et al. Abnormalities of gyration, heterotopias, tuberous sclerosis, focal cortical dysplasia, microdysgenesis, dysembryoplastic neuroepithelial tumour and dysgenesis of the archicortex in epilepsy: clinical, EEG and neuroimaging features in 100 adult patients. Brain 118, 629-660 (1995).

8. Mellerio, C. et al. Optimizing MR imaging detection of Type 2 focal cortical dysplasia: best criteria for clinical practice. Am. J. Neuroradiol. 33, 1932-1938 (2012).

9. Krsek, P. et al. Incomplete resection of focal cortical dysplasia is the main predictor of poor postsurgical outcome. Neurology 72 , 217-223 (2009).

10. Kloss, S., Pieper, T., Pannek, H., Holthausen, H. \& Tuxhorn, I. Epilepsy surgery in children with focal cortical dysplasia (FCD): results of long-term seizure outcome. Neuropediatrics 33, 21-26 (2002).

11. Hader, W. J. et al. Cortical dysplastic lesions in children with intractable epilepsy: role of complete resection. J. Neurosurg. Pediatr. 100, 110-117 (2004).

12. Phi, J. H. et al. Longitudinal analyses of the surgical outcomes of pediatric epilepsy patients with focal cortical dysplasia. J. Neurosurg. Pediatr. 6, 49-56 (2010).

13. Rowland, N. C. et al. A meta-analysis of predictors of seizure freedom in the surgical management of focal cortical dysplasia. J. Neurosurg. 116, 1035-1041 (2012). 
14. Chang, E. F. et al. Predictors of seizure freedom after surgery for malformations of cortical development. Ann. Neurol. 70, 151-162 (2011).

15. Chassoux, F. Stereoelectroencephalography in focal cortical dysplasia: a 3D approach to delineating the dysplastic cortex. Brain 123, 1733-1751 (2000).

16. Hamiwka, L. et al. Surgery for epilepsy due to cortical malformations: ten-year follow-up. Epilepsia 46, 556-560 (2005).

17. Allers, K. et al. The economic impact of epilepsy: a systematic review. BMC Neurol. 15, 245 (2015).

18. Begley, C. E. et al. The cost of epilepsy in the United States: an estimate from population-based clinical and survey data. Epilepsia 41, 342-351 (2000).

19. Itoh, A. et al. Breast disease: clinical application of US elastography for diagnosis. Radiology 239, 341-350 (2006).

20. Mitchell, G. F. et al. Arterial stiffness and cardiovascular events. Circulation 121, 505-511 (2010).

21. Murphy, M. C. et al. Decreased brain stiffness in Alzheimer's disease determined by magnetic resonance elastography. J. Magn. Reson. Imaging 34, 494-498 (2011).

22. Wuerfel, J. et al. MR-elastography reveals degradation of tissue integrity in multiple sclerosis. Neuroimage 49, 2520-2525 (2010).

23. Murphy, M. C. et al. Preoperative assessment of meningioma stiffness using magnetic resonance elastography. J. Neurosurg. 118, 643-648 (2013).

24. Kwan, P., Schachter, S. C. \& Brodie, M. J. Drug-resistant epilepsy. N. Engl. J. Med. 365, 919-926 (2011).

25. Cepeda, C. et al. Morphological and electrophysiological characterization of abnormal cell types in pediatric cortical dysplasia. J. Neurosci. Res. 72, 472-486 (2003).

26. Scharfman, H. E. The neurobiology of epilepsy. Curr. Neurol. Neurosci. Rep. 7, 348-354 (2007).

27. Chauvet, D. et al. In vivo measurement of brain tumor elasticity using intraoperative shear wave elastography. Eur. J. Ultrasound 37, 584-590 (2015).

28. Taylor, D. C., Falconer, M. A., Bruton, C. J. \& Corsellis, J. A. N. Focal dysplasia of the cerebral cortex in epilepsy. J. Neurol. Neurosurg. Psychiatry 34, 369-387 (1971).

29. Prevost, T. P. et al. Dynamic mechanical response of brain tissue in indentation in vivo, in situ and in vitro. Acta Biomater. 7, 4090-4101 (2011).

30. Budday, S. et al. Mechanical characterization of human brain tissue. Acta Biomater. 48, 319-340 (2017).

31. Schiavone, P. et al. In vivo measurement of human brain elasticity using a light aspiration device. Med. Image Anal. 13, 673-678 (2009).

32. Manduca, A. et al. Magnetic resonance elastography: non-invasive mapping of tissue elasticity. Med. Image Anal. 5, 237-254 (2001).

33. Vappou, J., Breton, E., Choquet, P., Willinger, R. \& Constantinesco, A. Assessment of in vivo and post-mortem mechanical behavior of brain tissue using magnetic resonance elastography. J. Biomech. 41, 2954-2959 (2008).

34. Urbanczyk, C. A., Palmeri, M. L. \& Bass, C. R. Material characterization of in vivo and in vitro porcine brain using shear wave elasticity. Ultrasound Med. Biol. 41, 713-723 (2015).

35. Koser, D. E., Moeendarbary, E., Hanne, J., Kuerten, S. \& Franze, K. CNS cell distribution and axon orientation determine local spinal cord mechanical properties. Biophys. J. 108, 2137-2147 (2015).

36. Kahn, E., Lane, M. \& Sagher, O. Eloquent: history of a word's adoption into the neurosurgical lexicon. J. Neurosurg. 127, 1461-1466 (2017).

37. Rosso, G. et al. Unravelling crucial biomechanical resilience of myelinated peripheral nerve fibres provided by the Schwann cell basal lamina and PMP22. Sci. Rep. 4, 7286 (2015).

38. Calder, I. M., Hill, I. \& Scholtz, C. L. Primary brain trauma in non-accidental injury. J. Clin. Pathol. 37, 1095-1100 (1984).

39. Fallah, A. et al. Resective epilepsy surgery for tuberous sclerosis in children. Neurosurgery 77, 517-524 (2015).

\section{Acknowledgements}

We would like to acknowledge Maria Garcia Roca, M.D. M.Sc., Richard Le, R. EEG T., and Patrick Wilson, R. EEG T. for their intraoperative assistance in the stereotactic localization of the tonometry measurements and Maria Inma Cobos Sillero, MD for her preparation of histopathological images for this manuscript.

\section{Author contributions}

A.F., T.S., X.M., H.V.V., W.H.Y., J.Y.W., G.W.M. contributed to the study design. A.F., T.S., H.V.V., W.H.Y., S.D.R., J.W.C., D.B., J.C.N., E.B. contributed to data collection and abstraction. A.F., G.M.I., C.T. contributed to the statistical analysis. A.F., X.M., H.W.P., H.V.V., W.H.Y., J.Y.W., N.S., B.E., A.C.W., G.M.I., A.G.W., C.T., G.W.M. contributed to the interpretation of the review. All authors reviewed and made substantial contributions to the preparation of the final manuscript.

\section{Competing interests}

Dr. Mathern is partly supported by Thomas P. and Nadia Q. Davies Chair in honor of Paul H. Crandall, M, for Epilepsy Research, and The National Institutes of Health R01 NS38992.. Dr. Wu serves on the professional advisory board for the Tuberous Sclerosis Alliance; has received honoraria from and serves on the scientific advisory board and the speakers' bureau for Novartis Pharmaceuticals Inc. and GW Pharmaceutical; and has received research support from the Tuberous Sclerosis Alliance, Novartis Pharmaceuticals Inc., Today and Tomorrow Children's Fund, Department of Defense/Congressionally Directed Medical Research Program, and the NIH. All other authors report no disclosures relevant to the manuscript.

\section{Additional information}

Correspondence and requests for materials should be addressed to A.F.

Reprints and permissions information is available at www.nature.com/reprints.

Publisher's note Springer Nature remains neutral with regard to jurisdictional claims in published maps and institutional affiliations. 
(c) (i) Open Access This article is licensed under a Creative Commons Attribution 4.0 International cc) License, which permits use, sharing, adaptation, distribution and reproduction in any medium or format, as long as you give appropriate credit to the original author(s) and the source, provide a link to the Creative Commons licence, and indicate if changes were made. The images or other third party material in this article are included in the article's Creative Commons licence, unless indicated otherwise in a credit line to the material. If material is not included in the article's Creative Commons licence and your intended use is not permitted by statutory regulation or exceeds the permitted use, you will need to obtain permission directly from the copyright holder. To view a copy of this licence, visit http://creativecommons.org/licenses/by/4.0/.

(C) The Author(s) 2020 